\title{
Perancangan Alat Pengangkat Sistem Hidrolik Tipe H Pada Tempat Pencucian Mobil Dengan Kapasitas Maximum 2.5 Ton
}

\author{
Ervini Meladiyani' ${ }^{1}$ Bayu Permana ${ }^{1}$, Marsudi $^{2}$, Ahmad Zayadi $^{3}$ \\ ${ }^{1}$ Program Studi Teknik Industri, Fakultas Teknik Industri, Universitas Suryadarma J1. Halim \\ Perdana Kusuma Jakarta Timur. \\ ${ }^{2}$ Program Studi Teknik Penerbangan, Fakultas Teknik Kedirgantaraan Universitas Marsekal \\ Suradarma, Jl. Halim Perdana Kusuma Jakarta Timur \\ ${ }^{3}$ Program Studi Teknik Mesin, Universitas Nasional Jakarta 12520
}

Korespondensi: zayadiahmad43@gmail.com

\begin{abstract}
Hydrolic system is tecknology wich uses fluid, work fluid that is used is oil with viscosity number of 10 SAE. This system work based on the principle of Pascal Low, that is if fluid given pressure, so that pressure will go to all direction by not added or less its pressure. By calculating of type H design hoist car system where as can be result teol that the permession strength of force material is bigger than the happenned strength of force material $\sigma_{\mathrm{b}}=9.25 \mathrm{~kg} / \mathrm{mm}^{2}>\tau_{\mathrm{b}}=0.34 \mathrm{~kg} / \mathrm{mm}^{2}$ and $\tau_{\mathrm{g}}=$ $70,98 \mathrm{~kg} / \mathrm{mm}^{2}>\tau_{\mathrm{g}}=10,46 \mathrm{~kg} / \mathrm{mm}^{2}$. So that the construction of type H design hoist car system by using of material BJ 37 is said saved and strong to be used. On this type $H$ design hoist car system based on SNI 05-3659-1995 which is about hydrolic fluid power with the rod end spherical eyes could be operated perfectly to hoist the car of 2.5 tonnes load. By desig specification of pump hydrolic capasity which is used 0.2 $\mathrm{dm}^{3} /$ minutes, power of pump as big $5.4 \mathrm{KW}$ and maximum of load capasity of 2.5 tonnes.
\end{abstract}

Keywords : Hydrolic system, type H design hoist, SNI

\section{PENDAHULUAN}

Rancangan suatu alat, pada dasarnya merupakan bagian perancangan (komponen)yang direncanakan dan dibuat untuk memenuhi kebutuhan mekanisme dari suatu peralatan. Dalam tahap-tahap perancangan tersebut, pertimbangan-pertimbangan yang perlu diperhatikan dalam memulai perancangan peralatan meliputi jenis-jenis pembebanan yang direncanakan, jenis-jenis tegangan yang ditimbulkan akibat pembebanan tersebut dan pemilihan kebutuhan material (bahan). Untuk mendapatkan bagian peralatan yang sesuai dengan kekuatannya, dilakukan pemilihan bahan dengan kekuatan yang sesuai dengan kondisi beban serta tegangan yang terjadi. Kekuatan yang direncanakan harus lebih kecil dari kekuatan bahan yang ditentukan dengan faktor keamanan sesuai dengan kebutuhan, agar hasil perancangan aman dan dapat bekerja dengan baik.Saat ini, dunia industri otomotif berkembang dengan sangat baik diberbagai bidang, termasuk di bidang kendaraan mobil. Hal ini juga terjadi pada industri pembuatan alat angkat mobil. Alat angkat yang dipakai pada mobil mengalami perkembangan yang cukup baik. Salah satu alat angkat mobil yang banyak dijumpai yaitu jenis alat angkat mobil yang menggunakan sistem hidrolik dimana penggunaannya sangat mudah dan efisien dalam membantu pekerjaan. Banyaknya jumlah kendaraan (mobil) yang ada pada saat ini menyebabkan meningkatnya permintaan akan pelayanan dan perawatan kendaraan tersebut terutama pada bagian bawah kendaraan. Hal ini tentunya menuntut pula tersedianya peralatan yang mendukung pekerjaan tersebut, sehingga menghasilkan efektifitas dan efisiensi dalam perawatan kendaraan. Berdasarkan masalah di atas untuk meningkatkan efektifitas dan efisiensi dalam perawatan kendaraan khususnya pada bagian bawah kendaraan maka akan dilakukan perencanaan sebuah alat angkat yang menggunakan sistem hidrolik tipe $\mathrm{H}$ dengan kapasitas beban sebesar 2.5 ton. Tujuan dari perancangan alat pengangkat mobil yang menggunakan sistem hidrolik tipe $\mathrm{H}$ dengan kapasitas angkat 2.5 ton adalah untuk mendapatkan spesifikasi teknis komponen alat pengangkat mobil yang menggunakan sistem hidrolik tipe $\mathrm{H}$ dengan kapasitas 2.5 ton dan untuk mengetahui jenis material batang yang ditahan oleh 
beban. Metode yang digunakan dalam perancangan adalah metode observasi, melakukan pengamatan dan pengukuran pada alat angkat system hidrolik yang ada di tempat pencucian mobil tersebut.Untuk mengetahui bagaimana sistem hidrolik itu bekerja dan dapat beroperasi dengan baik, aman, dan efisien sesuai dengan SNI, maka diperlukan perhitungan desain sehingga perancangan alat pengangkut sistem hidrolik dapat dioperasikan dan bekerja sesuai dengan kebutuhan dilapangan [1].

\section{TEORI DASAR}

\section{Pengertian Umum Mesin Pengangkat Mobil Dengan Sistem Hidrolik.}

Mesin pengangkat mobil dengan sistem hidrolik tipe $\mathrm{H}$ merupakan suatu sistem yang memanfaatkan tekanan fluida sebagai power (sumber tenaga) pada sebuah mekanisme kerjanya. Karena itu pada sistem hidrolik dibutuhkan power unit (motor dan pompa) untuk membuat fluida bertekanan. Kemudian fluida tersebut dialirkan sesuai dengan kebutuhan atau mekanisme yang diinginkan. Mesin hidrolik pengangkat mobil ini memiliki prinsip yang sama dengan dongkrak hidrolik. Perbedaannya terletak pada perbandingan luas penampang penghisap yang digunakan. Pada mesin pengangkat mobil, perbandingan antara luas penampang kedua penghisap sangat besar sehingga gaya angkat yang dihasilkan pada pipa penampang besar dan dapat digunakan untuk mengangkat mobil. Mesin hidrolik pengangkat mobil menggunakan pompa hidrolik yang digerakkan oleh motor listrik. Motor listrik ini dihubungkan langsung dengan pompa, dan pompa ini yang mendistribusikan fluida ke semua sistem. Pompa akan bekerja terus menerus selama motor listrik dihidupkan. Dan fluida yang dialirkan dengan pompa yang akan menuju ke silinder hidrolik sehingga mendorong piston hidrolik ke atas dan mobil terangkat ke atas. Ada dua macam peralatan yang biasanya digunakan dalam merubah energi hidrolik menjadi energi mekanik yaitu motor hidrolik dan actuator. Motor hidrolik mentransfer energi hidrolik menjadi energi mekanik dengan cara memanfaatkan aliran fluida dalam sistem kemudian merubahnya menjadi energi putaran yang dimanfaatkan untuk menggerakkan roda, transimisi, pompa dan lain-lain [2].

\section{Prinsip Kerja Sistem Hidrolik}

Prinsip kerja sistem hidrolik sebagaimana diperlihatkan dalam rangkaian hindrolik (gambar 1) menggunakan prinsip kerja "hukum pascal" yaitu, benda cair yang ada di ruang tertutup apabila diberi tekanan, maka tekanan tersebut akan dilanjutnya ke segala arah dengan sama besar, dan menggunakan fluida kerja berupa zat cair yang dipindahkan dengan pompa hidrolik untuk menjalankan suatu sistem tertentu. Jika ball valve yang menghubungkan antara pipa angin utama dibuka, maka secara cepat tekanan angin akan mengalir ketabung hidrolik tipe $\mathrm{H}$. Tekanan angin tersebut akan berinteraksi dengn oli yang terdapat dalam tabung hidrolik, maka akibat dari berinteraksinya tersebut piston dari dalam tabung tabung dari hidrolik tersebut akan secara perlahan keluar dari dalam tanah dan piston tersebut akan mendorong kendaraan yang berada diatasnya. Pompa hidrolik bekerja dengan cara menghisap oli dari tangki hidrolik dan mendorongnya kedalam sistem hidrolik dalam bentuk aliran (flow). Aliran ini yang dimanfaatkan dengan cara merubahnya menjadi tekanan. Tekanan dihasilkan dengan cara menghambat aliran oli dalam sistem hidrolik. Hambatan ini dapat disebabkan oleh orifice, silinder, motor hidrolik, dan actuator [10].

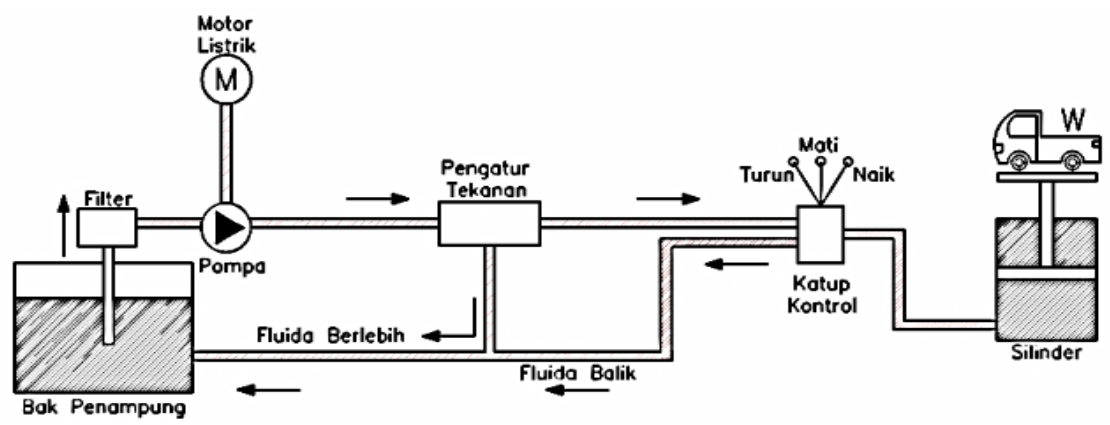

Gambar 1. Rangkaian Hidrolik 


\section{Formula Dasar Perancangan}

Formula dasar perancangan disesuaikan dengan Standar Nasional Indonesia (SNI) agar mesin pengangkat mobil sistem hidrolik dapat berfungsi dengan bai [4].

Tekanan yang terjadi pada silinder hidrolik diakibatkan oleh adanya beban yang diberikan pada ujung silinder hidrolik, tekanan tersebut dapat dihitung dengan formula:

$$
\mathrm{P}=\frac{\mathrm{F}}{\mathrm{A}}
$$

Dimana:

$\mathrm{P}=$ Tekanan, $\left(\mathrm{N} / \mathrm{mm}^{2}\right)$

$\mathrm{F}=$ Gaya yang terjadi, $(\mathrm{N})$

$\mathrm{A}=$ Luas penampang $\left(\mathrm{mm}^{2}\right)$

Dengan diketahuimya kecepatan angkat dan tinggi maksimum dari silinder hidrolik pada saat melakukan gerak kerja, maka debit aliran fluida pada silinder dapat dihitung/ ditentukan dengan persamaan (2).

$$
\mathrm{Qs}=\mathrm{V} \times \mathrm{A}
$$

Dimana:

Qs = Debit fluida, $\left(\mathrm{mm}^{3} /\right.$ detik$)$

$\mathrm{V}=$ Kecepatan angkat silinder $(\mathrm{mm} /$ detik $)$

$A=$ Luas penampang $\left(\mathrm{mm}^{2}\right)$

Berdasarkan perhitungan tekanan dan debit fluida pada silinder hidrolik, kita dapat memilih atau menentukan tekanan dan debit pompa yang akan digunakan dalam perancangan ini, dengan catatan bahwa tekanan dan debit pompa harus lebih besar dari kebutuhan pada silinder hidrolik. Kapasitas pompa adalah banyaknya cairan yang dapat dipindahkan oleh pompa setiap satuan waktu, perhitungan yang digunakan dalam perancangan sistem hidrolik ini dapat dihitung dengan persamaan (3).

$$
\mathrm{Kp}=\frac{\mathrm{Qp}}{\mathrm{Np}}
$$

Dimana :

$\mathrm{Kp}=$ Kapasitas pompa, $\left(\mathrm{dm}^{3} /\right.$ putaran $)$

$\mathrm{Qp}=$ Debit pompa, $\left(\mathrm{dm}^{3} /\right.$ menit $)$

$\mathrm{Np}=$ Putaran pompa $(\mathrm{rpm})$

Daya pompa

Daya pompa adalah besarnya energi persatuan waktu atau kecepatan pompa melakukan kerja dan daya pompa dapat dihitung jika rendemen (efisiensi) dari pompa diketahui, rendemen dapat dihitung dengan persamaan (4).

$$
\eta p=\eta v \times \eta m
$$

Dimana:

$\eta p=$ Randemen pompa $(\%)$

$\eta v=$ Randemen volumetrik $(\%)$

$\eta \mathrm{m}=$ Randemen mekanik ( \%)

Setelah randemen pompa yang digunakan diketahui maka daya pompa dapat dicari dengan menggunakan persamaan (5).

$$
\mathrm{Pp}=\mathrm{P} \times \mathrm{Qs}
$$

Dimana:

$\mathrm{Pp}=$ Daya pompa $(\mathrm{Kw})$

$\mathrm{P}=$ Tekanan $(\mathrm{N} / \mathrm{mm} 2)$

Qs = Debit pompa ( m3/detik)

Daya motor pompa merupakan salah satu parameter dalam menentukan performa motor yang akan digunakan pada perancangan mesin pengangkat sistem hidrolik ini. Daya motor pompa dapat dihitung dengan persamaan (6).

$$
\text { Daya motor }=\frac{P p}{\eta m}
$$

Dimana : 
$\mathrm{Pp}=$ Daya pompa $(\mathrm{Kw})$

$\eta \mathrm{m}=$ Randemen mekanik $(\%)$

Pada silinder hidrolik akan dihitung tentang tegangan yang terjadi pada poros silinder hidrolik, bahan yang dipakai, dan juga akan dihitung kemungkinan (tekukan) yang terjadi pada piston silindernya. Tegangan tekan yang terjadi pada silinder hidrolik dapat dihitung dengan persamaan (7).

$$
\sigma_{t}=\frac{\mathrm{F}}{\mathrm{A}}
$$

Dimana:

$\sigma \mathrm{t}=$ Tegangan tekan $\left(\mathrm{N} / \mathrm{mm}^{2}\right)$

$\mathrm{F}=$ Tekanan pada silinder $(\mathrm{N})$

A $=$ Luasan area silinder $\left(\mathrm{mm}^{2}\right)$

Perhitungan bahan yang digunakan pada silinder hidrolik dapat diketahui dengan cara mengkalikan tekanan yang terjadi dengan diameter luar silinder, lalu dibagi dengan tebal dinding silinder. Sehingga didapat hasil dari tegangan yang terjadi, kemudian bisa dipilih bahan yang digunakan dengan syarat tegangan izin bahan harus lebih besar daripada tegangan yang terjadi.

$$
\sigma=\frac{\operatorname{Pxr}}{\mathrm{t}}
$$

Dimana:

$\sigma=$ Tegangan yang terjadi $(\mathrm{N} / \mathrm{mm} 2)$

$\mathrm{P}=$ Tekanan $(\mathrm{N} / \mathrm{mm} 2)$

$\mathrm{r}=\operatorname{Jari}-\mathrm{jari}(\mathrm{mm})$

$\mathrm{t}=$ Tebal $(\mathrm{mm})$

Dalam perancangan mesin pengangkat mobil sistem hidrolik ini ditemukan berbagai permasalahan yang bersangkutan dengan kekuatan bahan.Contohnya : dalam penentuan ukuran dan bahan bagi batang pengangkat serta bagian-bagiannya. Selain itu juga untuk silinder piston ditemukan permasalahan terhadap kemungkinan tekukan di piston rodnya, juga tegangan yang terjadi yang diakibatkan oleh tekanan fluida pada dinding silinder hidrolik. Adapun perhitungan kekuatan bahan yang dipakai pada rancangan ini meliputi tegangan tarik (tekan), tegangan bengkok. tegangan geser dan lendutan.

Tegangan yang diizinkan adalah tegangan maksimum yang boleh terjadi pada suatu bahan agar bahan tersebut tidak mengalami kepatahan atau deformasi plastis.Hal ini dapat dimengerti, karena di dalam perencanaan perancangan mesin pengangkat mobil sistem hidrolik ini harus bisa menentukan ukuran-ukuran atau beban yang sesuai dengan perhitungan, sehingga konstruksi yang direncanakan tidak mengalami kegagalan.

Untuk memperhitungkan tegangan yang diizinkan dapat pula kita memperhitungkan terhadap tegangan maksimum dengan suatu faktor yang dinamakan faktor keamanan, diperoleh dari persamaan (9).

$$
\sigma \text { ijin }=\frac{\sigma u}{S f}
$$

Dimana:

$$
\begin{aligned}
& \sigma \text { ijin }=\text { Tegangan izin }\left(\mathrm{N} / \mathrm{mm}^{2}\right) \\
& \sigma \mathrm{u}=\text { Kekuatan tarik dari bahan }(\mathrm{N} / \mathrm{mm} 2) \\
& \mathrm{Sf}=\text { Angka keamanan }
\end{aligned}
$$

Secara umum tegangan adalah gaya yang ditahan oleh setiap satuan luasan. Tegangan tarik adalah besar gaya tarik dibagi dengan luasan penampang suatu benda, tegangan tarik dituliskan dengan simbol $\sigma$ t. Sementara tegangan tekan adalah tegangan yang terjadi di dalam suatu batang apabila gaya-gaya luar yang bekerja padanya adalah gaya-gaya tekan, tegangan tekan dituliskan dengan simbol $\sigma$ d. Tegangan tarik (tekan) dapat dicari melalui persamaan (10).

$$
\sigma \mathrm{t}=\sigma \mathrm{d}=\frac{\mathrm{F}}{\mathrm{A}}
$$

Dimana: 
$\sigma \mathrm{t}=$ Tegangan tarik $\left(\mathrm{N} / \mathrm{mm}^{2}\right)$

$\sigma \mathrm{d}=$ Tegangan tekan $(\mathrm{N} / \mathrm{mm} 2)$

$\mathrm{F} \quad=$ Gaya yang bekerja $(\mathrm{N})$

$\mathrm{A}=$ Luas penampang, $(\mathrm{mm} 2)$

Untuk pemilihan bahan dalam rancangan ini selalu harus ditemukan/ditentukan kekuatan tariknya.Misalnya dalam perhitungan setelah dikalikan angka keamanan didapat tegangan tarik $300 \mathrm{~N} / \mathrm{mm}^{2}$, maka dipilih bahan dengan kekuatan tarik di atas tegangan yang terjadi. Misalnya kita pilih material St 37 yang berarti material ini mempunyai kekuatan tarik sebesar $37 \mathrm{~kg} / \mathrm{mm}^{2}\left(362.97 \mathrm{~N} / \mathrm{mm}^{2}\right)$. Berdasarkan perhitungan, konstruksi ini bisa dinyatakan aman.

Seperti halnya tegangan tarik, tegangan geser adalah gaya geser per satuan luas geser. Gayanya bisa gaya tarik atau gaya tekan. Tegangan geser terjadi karena benda mendapat gaya melintang dan ditahan oleh suatu luasan. Dengan kata lain tegangan geser $=($ Gaya geser ) / (Luasan geser). Simbol tegangan geser adalah ( $\tau \mathrm{g})$. Tegangan geser dapat dicari dengan menggunakan persamaan (12).

$$
\mathrm{Tg}=\mathrm{m} /(\mathrm{m}+1) \times(\sigma) \tilde{t}
$$

Dimana:

$\tau \mathrm{g}=$ Tegangan geser yang terjadi $\left(\mathrm{N} / \mathrm{mm}^{2}\right)$.

$(\sigma)^{\tilde{t}}=$ Tegangan tarik izin yang didapat dari tegangan tarik murni dibagi dengan angka keamanan, $\left(\mathrm{N} / \mathrm{mm}^{2}\right)$.

$\mathrm{m}$ = Angka poison, besarnya tergangtung dari jenis bahan, misalnya untuk baja nilainya berkisar antara $(3.3-3.6)$.

Tegangan ini terjadi karena sebuah beban atau gaya dengan suatu jarak tertentu sehingga menimbulkan moment yang disebut dengan moment bengkok. Luasan yang menahan moment tersebut disebut moment tahanan bengkok, mempunyai simbol $\mathrm{Wb}$.

Misalnya untuk balok dengan panjang, lebar dan tebalnya masing-masing dalam (mm) a $\mathrm{x}$ b x c, dan gaya yang bekerja diujung a sebesar $F(N)$ melintang terhadap panjang dan lebarnya, maka:

$$
\mathrm{Mb}=\mathrm{F} \times \mathrm{a}(\mathrm{N} \cdot \mathrm{mm})
$$

Dimana:

$$
\begin{aligned}
\mathrm{Mb} & =\text { Momen bengkok }(\mathrm{N} . \mathrm{mm} 2) \\
\mathrm{F} & =\text { Beban }(\mathrm{N}) \\
\mathrm{A} & =\text { Luasan area }(\mathrm{mm} 2)
\end{aligned}
$$

Dari rumus diatas dapat ditentukan tegangan bengkok yang terjadi dengan formula:

$$
\sigma b=\tilde{t}=\mathrm{Mb} / \mathrm{Wb}
$$

Dimana:

$$
\begin{aligned}
& \sigma \mathrm{b}=\text { Tegangan bengkok }\left(\mathrm{N} / \mathrm{mm}^{2}\right) \\
& \tilde{\sigma t}=\text { Tegangan tarik izin }\left(\mathrm{N} / \mathrm{mm}^{2}\right) \\
& \mathrm{Mb}=\text { Moment bengkok }(\mathrm{N} \cdot \mathrm{mm}) \\
& \mathrm{Wb}=\text { Moment tahanan bengkok }\left(\mathrm{mm}^{2}\right)=1 / 6\left[\mathrm{~b} \cdot \mathrm{h}^{\wedge} 2\right] \\
& \text { dengan } \\
& \mathrm{b} \quad=\text { Lebar penampang }(\mathrm{mm}) \\
& \mathrm{h} \quad=\text { Tinggi penampang }(\mathrm{mm})
\end{aligned}
$$

Besar atau kecilnya nilai tegangan bengkok sama dengan tegangan tarik izin.

Bila suatu batang mendapat pembebanan, maka batang tesebut akan mengalami lendutan (defleksi). Besarnya lendutan dapat dicari dengan menggunakan metode persamaan integral atau bidang moment. Untuk metode bidang moment, kita perlu mengetahui Modulus Elastisitas (E), inersia (I), juga letak gaya-gaya pada batang.

Dengan mengetahui letak gaya-gaya tersebut, perhitungan besarnya moment dapat dicari pada masing-masing titik, kemudian dibuat bidang moment dengan luas (A). Modulus elastisitasnya (E) diketahui dari jenis bahannya. Inersia (I) dicari dengan menghitung penampang batang terhadap bebannya. Kemudian dicari titik berat dari masing-masing luas 
bidang moment dan ditarik suatu jarak ke ujung pembebanan $[\mathrm{x} 1, \mathrm{x} 2, \mathrm{x} 3, \mathrm{x} 4, \ldots \ldots ., \mathrm{xn}]$, maka besarnya pelenturan diujung batang seperti pada persamaan (15).

$$
\mathrm{Y}=\frac{\mathrm{X} 1 \cdot \mathrm{A} 1+\mathrm{X} 2 \cdot \mathrm{A} 2+\mathrm{X} 3 \cdot \mathrm{A} 3+\mathrm{X} 4 \cdot \mathrm{A} 4+\cdots \mathrm{Xn} \cdot \mathrm{An}}{\mathrm{E} \cdot \mathrm{I}}
$$

Dimana:

$\mathrm{Y}=$ Pelenturan yang terjadi $(\mathrm{mm})$

$\mathrm{E}=$ Moment inersia $\left(\mathrm{Kg} \cdot \mathrm{m}^{2}\right)$

$\mathrm{A}=$ Luasan area $(\mathrm{mm} 2)$

$\mathrm{X} 1=$ Titik-titik pembebanan

Pada dinding silinder piston akan timbul tekanan yang diakibatkan oleh fluida yang bekerja, formula yang diguanakan untuk menghitung tegangan pada dinding silinder bisa menggunakan formula umum untuk vessel, dimana formula tersebut seperti di bawah ini:

$$
\frac{\mathrm{P}}{\mathrm{t}}=\frac{\sigma 1}{\mathrm{r} 1}+\frac{\sigma 2}{\mathrm{r} 2}
$$

Untuk vessel berbentuk silinder maka formula yang digunakan adalah:

$$
\sigma=\frac{\text { P.t }}{\mathrm{r}}
$$

Dimana :

$\sigma=$ Tegangan yang diizinkan pada silinder $\left(\mathrm{N} / \mathrm{mm}^{2}\right)$

$\mathrm{P}=$ Tekanan dalam silinder $\left(\mathrm{N} / \mathrm{mm}^{2}\right)$

$\mathrm{t}=$ Tebal plat $(\mathrm{mm})$

$\mathrm{r}=$ Jari-jari $(\mathrm{mm})$

Dalam desain konstruksi mesin, besarnya angka keamanan harus lebih besar dari 1(satu).Faktor keamanan diberikan agar desain konstruksi dan komponen mesin dengan tujuan agar desain tersebut mempunyai ketahanan terhadap beban yang diterima. Pemilihan SF harus didasarkan pada jenis beban, jenis material, proses pembuatan/manufaktur, jenis tegangan, jenis kerja yang dilayani dan bentuk komponen.

Makin besar kemungkinan adanya kerusakan pada komponen mesin, maka angka keamanandiambil makin besar. Angka keamanan beberapa material dengan berbagai beban dapat dilihat pada Tabel 1 [3].

Tabel 1. Safety factor material.

\begin{tabular}{|c|l|c|c|c|}
\hline No & \multicolumn{1}{|c|}{ Material } & Steady Load & Live Load & Shock Load \\
\hline 1. & Cost iron & $5-6$ & $8-12$ & $16-20$ \\
\hline 2. & Wronght iron & 4 & 7 & $10-15$ \\
\hline 3. & Steel & 4 & 8 & $12-16$ \\
\hline 4. & Soft material and alloys & 6 & 9 & 15 \\
\hline 5. & Leather & 9 & 12 & 15 \\
\hline 6. & Timber & 7 & $10-15$ & 20 \\
\hline
\end{tabular}

\section{METODOLOGI PERANCANGAN}

\section{Diagram Alir}

Proses perancangan mesin pengangkat mobil sistem hidrolik dengankapasitas 2.5 ton dapat diuraikan sesuai tahapan pada diagram alir berikut ini [9].

\section{Perhitungan Sistem Hidrolik}

Pada perancangan mesin pengangkat mobil sistem hidrolik ini, ditentukan beberapa batasan berupa berat mobil, berat piston, dan berat landasan. Agar perancangan dapat bekerja sesuai dengan rangkaian alat dan beban yang ditentukan. Yang akan dihitung dalam perencanaan adalah tekanan dan debit pada silinder hidrolik serta kapasitas pompa dan daya motor[10]. Adapun data yang digunakan untuk menghitung tekanan dan debit yang terjadi pada silinder hidrolik, yakni:

- Berat mobil $(\mathrm{W} 1)=2.5$ ton $=2500 \mathrm{~kg}$

- Berat Piston $(\mathrm{W} 2)=100 \mathrm{~kg}$

- $\quad$ Landasan Type H (W3) $=150 \mathrm{~kg}$ 
- Diameter silinder Piston (D1) $=320 \mathrm{~mm}$

- Diameter silinder $(\mathrm{D} 2)=280 \mathrm{~mm}$

- Panjang langkah piston(s) $=1500 \mathrm{~mm}$

- Waktu angkat maksimum $(\mathrm{t})=60$ detik

- Kecepatan Angkat (v) $=10 \mathrm{~m} / \mathrm{menit}$

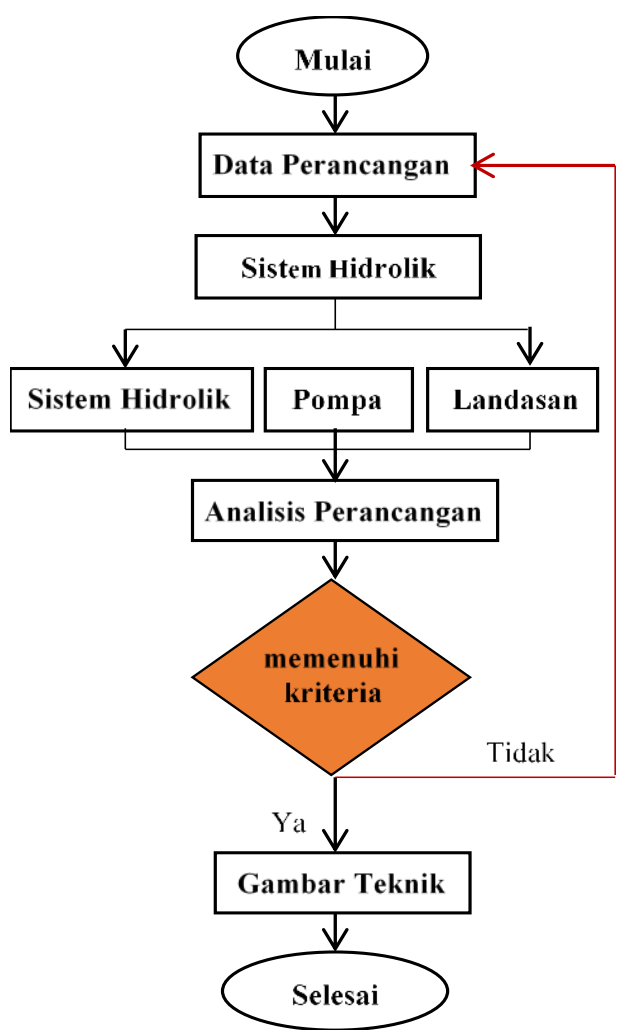

Gambar 2. Diagram alir perancangan mesin pengangkat mobil sistem hidrolik kapasitas 2.5 ton.

\section{HASIL DAN PEMBAHASAN}

\section{Perhitungan Bagian Hidrolik}

Pada perancangan mesin pengangkat mobil system hidrolik ini, ditentukan beberapa batasan seperti berat mobil, berat piston, dan berat landasan. Agar perancangan dapat bekerja sesuai dengan rangkaian alat dan beban yang ditentukan [2].

Data yang telah didapat, digunakan untuk menghitung tekanan dan debit yang terjadi pada silinder hidrolik, dimana:

- Berat mobil (W1) $=2.5$ ton $=2500 \mathrm{~kg}$.

- Berat piston (W2) $=100 \mathrm{~kg}$.

- Beratlandasan $(\mathrm{W} 3)=150 \mathrm{~kg}$.

Berat total keseluruhan $(\mathrm{F})=(\mathrm{W} 1+\mathrm{W} 2+\mathrm{W} 3)=[2500(\mathrm{~kg})+100(\mathrm{~kg})+150(\mathrm{~kg})]$

$$
(\mathrm{F})=2750 \mathrm{~kg}=27.500 \mathrm{~N}
$$

Tekanan yang terjadi pada saat silinder hidrolik bekerja dapat dihitung dengan cara membagi beban yang terjadi dengan luasan area silinder hidrolik tersebut adalah 0.34 $\mathrm{N} / \mathrm{mm}^{2}$. Dengan diketahuinya kecepatan angkat dan tinggi maksimum dari piston hidrolik selama satu menit, maka debit aliran fluida pada silinder adalah Qs $=\mathrm{v} \times \mathrm{A}=$ $3.08 \mathrm{dm}^{3} /$ detik. Beban pada poros silinder yang diterima sebesar $2.750 \mathrm{~kg}(27.500$ $\mathrm{N})$.Luasan area pada poros silinder diketahui $\mathrm{A}=80.384 \mathrm{~mm}^{2}$. Tegangan tekan yang terjadi pada poros silinder sebesar $0.34 \mathrm{~N} / \mathrm{mm}^{2}$. Agar poros silinder lebih aman terhadap tegangan tekan yang terjadi maka tegangan tekan dikalikan dengan angka keamanan( Sf ) yang diambil nilai 4 . Karena beban yang diterima beban statis atau tidak bergerak. Sehingga diperoleh nilai tegangan tekan yang terjadi pada piston silinder sebesar $0,34 \times 4=$ 
$1,36 \mathrm{~N} / \mathrm{mm}^{2}$, dimana ukuran silinder dan poros silinder hindrolik sebagaimana diperlihatkan pada gambar 3 .

\section{Perhitungan Kekuatan Silinder}

Pada silinder hidrolik karena menahan beban seberat 2.5 ton $(2.500 \mathrm{~kg})$, maka akan terjadi tegangan bengkok yang diakibatkan oleh beban tersebut. Dimana tegangan bengkok yang terjadi adalah $0.34 \mathrm{~N} / \mathrm{mm}^{2}$. Pada silinder hidrolik menggunakan baja 37 dengan tegangan bengkok izin $\widetilde{\sigma b}=3700 \mathrm{Mpa}=370 \mathrm{~N} / \mathrm{mm}^{2}=37 \mathrm{Kg} / \mathrm{mm}^{2}$. Untuk memperkuat nilai

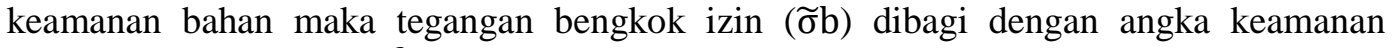
sehingga $\widetilde{\sigma} b=\frac{37\left(\mathrm{~kg} / \mathrm{mm}^{2}\right)}{4}=9.25 \mathrm{Kg} / \mathrm{mm}^{2}$.

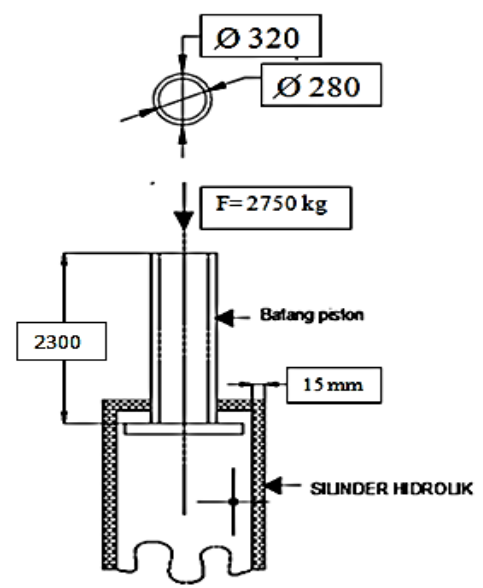

Gambar 3. Silinder dan poros silider hidrolik.

Dari hasil perhitungan di atas tegangan bengkok yang terjadi lebih kecil dari pada tegangan bengkok yang diziinkan $\left(\sigma \mathrm{b}=0.34 \mathrm{Kg} / \mathrm{mm}^{2}>\widetilde{\sigma} \mathrm{b}=9.25 \mathrm{Kg} / \mathrm{mm}^{2}\right)$. Maka silinder hidrolik dinyatakan kuat atau aman untuk mengangkat beban sebesar 2.5 ton.

\section{Pompa dan Motor Hidrolik yang Digunakan}

Berdasarkan perhitungan tekanan di dalam silinder dan debit fluida pada silinder, sehingga dapat memilih atau menentukan tekanan dan debit pompa yang akandi gunakan. Dengan catatan bahwa tekanan dan debit pompa juga harus lebih besar dari kebutuhan silinder, dimana:

- Pompa yang digunakan memiliki tekanan 15 bar $\left(1.5 \mathrm{~N} / \mathrm{mm}^{2}\right)$.

- Debit aliran pada pompa sebesar 150 liter/menit(150 dm³/menit).

- Putaran motor pompa sebsar $750 \mathrm{rpm}$.

- Efisiensi volumetrik dan mekanik sebesar $90 \%$ dan $95 \%$.

Pada perancangan mesin hidrolik setelah melakukan perhitungan, kapasitas pompa yang digunakan diketahui sebesar $\mathrm{Kp}=\frac{\mathrm{Qp}}{\mathrm{Np}}=0.2 \mathrm{dm}^{3} /$ putaran. Dengan kapasitas pompa sebesar $0,2 \mathrm{dm}^{3} /$ putaran, maka didapat hasil perhitungan daya pompa yang terjadi sebesar $\mathrm{Pp}^{\prime}=\mathrm{P} \times \mathrm{Q}=4.62 \mathrm{~kW}$. Daya pompa yang digunakan dapat diketahui dengan cara daya pompa yang digunakan dibagi dengan eifsiensi pompa $\mathrm{Pp}=\frac{\mathrm{Pp} \prime}{\mathrm{np}}=5.40 \mathrm{~kW}$. Motor hidrolik pompa yang digunakan mempunyai randemen mekanis sebesar $95 \%$, maka daya motornya sebesar daya motor $=\frac{\text { daya pompa }}{\text { randemen mekanis }}=5.68 \mathrm{kw}$. Berdasarkan perhitungan pada bab ini, maka bisa dipilih motor pompa yang digunakan untuk mendistribusikan fluida pada system hidrolik ini sebesar $8 \mathrm{~kW}$, atau setara dengan $8 \mathrm{hp}$.

\section{Perhitungan Kekuatan Landasan}

Landasan pengangkat ini dirancang dengan panjang dan lebar tumpuan mobil sebagai berikut:

- Panjang dan lebar minimum

$$
\begin{aligned}
& =2.500 \mathrm{~mm} \times 1.500 \mathrm{~mm} \\
& =2.750 \mathrm{~mm} \times 1.800 \mathrm{~mm}
\end{aligned}
$$

Jadi landasan ini dapat melayani pencucian mobil sesuai panjang dan lebar ketentuan ukuran diatas. Pada batang penahan besar ditentukan ukuran-ukuran yang akandigunakan 
sebagai berikut:

- Lebar batang penahan besar (b1) $\quad=500 \mathrm{~mm}$.

- Tinggi batang penahan besar (h1) $=2400 \mathrm{~mm}$.

- Panjang batang penahan besar (p1) $=2500 \mathrm{~mm}$.

- Beban keseluruhan $(\mathrm{F})\left(\mathrm{w}_{1}+\mathrm{w}_{2}+\mathrm{w}_{3}\right) \quad=2.750 \mathrm{~kg}(27.500 \mathrm{~N})$.

Sehingga moment bengkok yang terjadi pada plat batang penahan besar adalah sebesar 134.750.000 Nmm. Tegangan bengkok = tegangan tarik yang diizinkan adalah sebesar $\tilde{\sigma} t=9.25 \mathrm{~kg} / \mathrm{mm}^{2}=92.5 \mathrm{~N} / \mathrm{mm}^{2}$. Tebal plat batang penahan besar $5 \mathrm{~mm}$ dengan bahan BJ 34. Tegangan geser bahan yang diizinkan adalah sebesar $70.98 \mathrm{~N} / \mathrm{mm}^{2}$. Tegangan geser yang terjadi adalah sebesar $\mathrm{\tau g}=1.46 \mathrm{~N} / \mathrm{mm}^{2}$.

Dari hasil perhitungan di atas tegangan geser izin pada bahan lebih besar dari pada tegangan geser yang terjadi $\left(\tilde{\tau} g=70,98 \mathrm{~N} / \mathrm{mm}^{2}>\tau g=1.46 \mathrm{~N} / \mathrm{mm}^{2}\right.$ ). Jadi konstruksi batang penahan besar dengan bahan BJ 34 dinyatakan aman.

Pada plat batang penahan kecil ditentukan juga ukuran-ukuran yang digunakan sebagai berikut:

- Lebar batang penahan kecil (b2) $\quad=400 \mathrm{~mm}$

- Tinggi batang penahan kecil (h2) $\quad=2.300 \mathrm{~mm}$

- Panjang batang penahan kecil $(\mathrm{p} 2) \quad=2.400 \mathrm{~mm}$

- Beban keseluruhan $(\mathrm{F})(\mathrm{w} 1+\mathrm{w} 2+\mathrm{w} 3)=2.750 \mathrm{~kg}(27.500 \mathrm{~N})$

Sehingga moment bengkok yang terjadi pada plat batang penahan kecil adalah sebesar $\mathrm{Mb}=134.750 .000 \mathrm{Nmm}$. Tebal plat batang penahan kecil = $150 \mathrm{~mm}$ dengan bahan BJ 34 tegangan bengkok bahan $=$ tegangan tarik yang diizinkan adalah sebesar $\tilde{\sigma} t=$ $9.25 \mathrm{~kg} / \mathrm{mm}^{2}=92.5 \mathrm{~N} / \mathrm{mm}^{2}$. Tegangan geser yang diizinkan adalah sebesar $\tilde{\tau} g=$ $\frac{3,3}{3,3+1} \times 92.5 \mathrm{~N} / \mathrm{mm}^{2}=70,98 \mathrm{~N} / \mathrm{mm}^{2}$. Tegangan geser yang terjadi adalah sebesar $\tau g=\frac{F}{A}=1.46 \mathrm{~N} / \mathrm{mm}^{2}$.

Dari hasil perhitungan di atas tegangan geser izin pada bahan lebih besar dari pada tegangan geser yang terjadi $\left(\tilde{\tau} g=70.98 \mathrm{~N} / \mathrm{mm}^{2}>\tau g=1.46 \mathrm{~N} / \mathrm{mm}^{2}\right)$. Jadi konstruksi batang penahan besar dengan bahan BJ 37 dinyatakan aman.

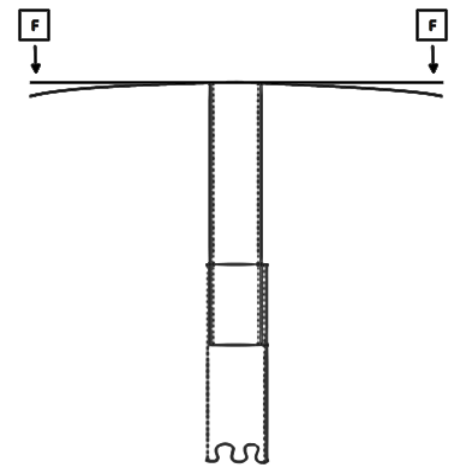

Gambar 4. Diagram lendutan batang penahan.

Landasan berkaret dengan kemiringan dan lendutan yang telah di hitung, maka dapat di tentukan tinggi minimum landasan berkaret yaitu dengan menjumlahkan kedua hasil yang didapat, tinggi minimal landasan berkaret adalah $66.5 \mathrm{~mm}$. Untuk mencegah bagian bawah mobil terjadi kerusakan dan karena tinggi minimum didapat $66.5 \mathrm{~mm}$ bagian bawah mobil akan menyentuh landasan, maka tinggi landasan berkaret yang digunakan dibuat dengan ukuran tinggi $50 \mathrm{~mm}$.

Perhitungan beban-beban yang bekerja pada pelat kaki besar dan kecil menggunakan prinsip-prinsip mekanika teknik yaitu berupa keseimbangan gaya dan keseimbangan moment, sehingga diperoleh MA sebesar -129.250.000 Nm dan RAVm sebesar 27.500 N. Karena tinggi minimum bagian bawah mobil akan menyentuh landasan, maka tinggi landasan berkaret yang digunakan dibuat dengan ukuran $50 \mathrm{~mm}$. Hal ini sebagaimana diperlihatkan pada diagram lendutan penahan (gambar 4) dan landasan berkaret (gambar 5). Untuk bahan pin dipilih baja (St 37) dimana $\sigma \mathrm{t}=37 \mathrm{~kg} / \mathrm{m}^{2}$, dengan angka keamanan 
(Sf) adalah 4, tegangan geser izinnya adalah sebesar $92.5 \mathrm{~N} / \mathrm{mm}^{2}$. Diameter pin dihitung dengan menggunakan formula $D=\sqrt{\frac{4 \times 420.750}{\pi \times 70.98}}=86.89 \mathrm{~mm}$.

Berdasarkan perhitungan di atas, diameter pin yang digunakan sebesar $87 \mathrm{~mm}$ dan tegangan geser yang terjadi sebesar $92.5 \mathrm{~N} / \mathrm{mm}^{2}$, dengan demikian diameter pin $87 \mathrm{~mm}$ dinyatakan aman karena $92.5 \mathrm{~N} / \mathrm{mm}^{2}>70.98 \mathrm{~N} / \mathrm{mm}^{2}$.

Garpu penjepit pin, sebagaimana yang telah dijelaskan sebelumnya. Diketahui gaya-gaya yang bekrja pada pin, ditik $\mathrm{X}$ terjadi tegangan tarik sedangkan di titik $\mathrm{Y}$ terjadi tegangan desak dan di titik a terjadi tegangan bengkok dan geser. Tegangan tarik yang terjadi akibat $\mathrm{F}=420.750 \mathrm{~N}$ adalah:

- Luas antara di titik a sebesar $=3436.5 \mathrm{~mm}^{2}$

- Tegangan tarik yang terjadi pada garpu penjepit pin sebesar $122.453 \mathrm{~N} / \mathrm{mm}^{2}$

- Tegangan desak yang terjadi pada garpu penjepit pin sebesar $244.871 \mathrm{~N} / \mathrm{mm}^{2}$

- Momen bengkok yang terjadi pada garpu penjepit pin sebesar $=147.262 .500 \mathrm{Nm}$ dan tegangan bengkok yang terjadi $=4.045 \mathrm{~N} / \mathrm{mm}^{2}$

- Tegangan geser yang terjadi $=10.46 \mathrm{~N} / \mathrm{mm}^{2}$, dengan tegangan geser izinnya $=$ $3.2398 \mathrm{~N} / \mathrm{mm}^{2}$

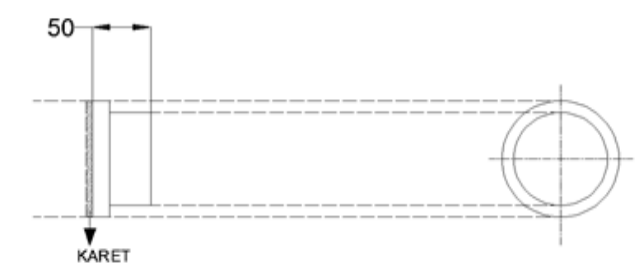

Gambar 5. Karet landasan.

Dari keempat gaya yang telah terjadi pada garpu penjepit pin, maka gaya yang terbesar diakibatkan oleh gaya desak sebesar $244.87 \mathrm{~N} / \mathrm{mm}^{2}$. Maka untuk garpu penjepit pin dipilih bahan BJ 37 dengan kekuatan tarik sebesar $37 \mathrm{~kg} / \mathrm{mm}^{2}\left(92.5 \mathrm{~N} / \mathrm{mm}^{2}\right)$ agar konstruksi mesin pengangkat aman dari yang tidak diinginkan. Gaya-gaya yang bekerja pada garpu penjepit pin yaitu, di $(\mathrm{X})$ terjadi tegangan tarik dengan gaya $\left(\mathrm{F}_{2}\right)$, seperti pada $\left(\mathrm{M}_{2}\right)$ di pin. Sedangkan di (Y) terjadi tegangan desak, sementara di (a) terjadi tegangan bengkok dan geser. Gaya tarik terjadi sebesar $\left(\mathrm{F}_{1}\right)=42.75 \mathrm{~N}$.

\section{KESIMPULAN}

Dari hasil perhitungan terhadap poros / piston silinder hidrolik maka tegangan bengkok yang diizinkan $\left(\overline{\sigma_{b}}\right)$ untuk bahan lebih besar dari tegangan yang terjadi $\left(\sigma_{b}\right)$, yaitu $\left(\overline{\sigma_{b}}=9.25 \frac{\mathrm{kg}}{\mathrm{mm}^{2}}>\sigma_{b}=0.3421 \frac{\mathrm{kg}}{\mathrm{mm}^{2}}\right)$, maka piston silinder hidrolik dinyatakan kuat dan aman untuk mengangkat beban sebesar 2.5 ton. Hasil perhitungan terhadap tebal plat dan batang penahan beban mobil didapat bahwa tegangan geser izin pada bahan lebih besar dari pada tegangan geser yang terjadi $\left(\overline{\tau_{g}}=70,98 \frac{\mathrm{N}}{\mathrm{mm}^{2}}>\tau_{g}=10,46 \frac{\mathrm{N}}{\mathrm{mm}^{2}}\right)$, sehingga konstruksi batang penahan dengan bahan BJ 37 dinyatakan kuat dan aman untuk mengangkat beban sebesar 2,5 ton. Untuk garpu penjepit pin pada batang penahan dengan bahan BJ 37 dinyatakan kuat dan aman untuk digunakan, karena tegangan geser / desak $\left(\overline{\tau_{g}}\right)$ bahan yang diizinkan lebih besar dari tegangan geser yang ter jadi $\left(\tau_{g}\right)$ yaitu $\overline{\tau_{g}}=244.9 \frac{\mathrm{N}}{\mathrm{mm}^{2}}>\tau_{g}=$ $92.5 \frac{\mathrm{N}}{\mathrm{mm}^{2}}$. Berdasarkan hasil perhitungan daya motor hidrolik pompa ( Hp motor ) sebesar $8 \mathrm{~kW}$ atau dengan $8 \mathrm{HP}$ mampu untuk mendistribusikan fluida pada sistem pompa hidrolik ini.

\section{DAFTAR PUSTAKA}

[1] Andrew Parr, Hidrolika dan Pneumatika Pedoman Untuk Insinyur, Erlangga, Jakarta Tahun 2003. 
[2] Hagedorn, J.J.M., Konstruksi Mesin 1, Rosda Jaya Putra, Jakarta 1992

[3] Hibbeller, R.C, 1999, Analisa Struktur, PT Prenhallindo

[4] Khurmi R.S. \& Gupta J.K. A Text Book of Machine Design, Eurasia Publishing House, New Delhi Tahun 1983

[5] http://mechanic-mechanicalengineering.blogspot.co.id/2011/03/pompa-pump.html

[6] http://www.steelindopersda.com/2014/06/pembagian-dan sifat-sifat-baja.html

[7] Sularso, Kiyokatsu Suga, DasarPerencanaan dan Pemilihan Elemen Mesin, Pradya Paramita, Jakarta

[8] Sato,G.T.,N. Sugiarto H, Menggambar Mesin, Pradya Paramita, Jakarta, 1994.

[9] Yohanes, Tugas Akhir Perancangan Mesin Pengangkat Mobil Dengan Kapasitas 8 Ton, Universitas Nasional, Jakarta 1994. 